\title{
RÉPLICA
}

\section{MAESTRO DE ESPÍAS. \\ RÉPLICA A CÉSAR E. VALDEZ ${ }^{1}$}

Heribert von Feilitzsch

A 1 leer la reseña de mi libro, Félix A. Sommerfeld: maestro Ade espias en México, 1908 a 1914, se podría concluir que el título debería haber sido diferente. El crítico César E. Valdez sostiene que

Sommerfeld se convierte en el nodo que conecta a todos los personajes importantes de la primera guerra mundial, desde Guillermo II, diplomáticos estadounidenses, alemanes y británicos, empresarios mexicanos, periodistas, caudillos, entre otros. Por sus manos, nos reitera muchas veces el autor, pasaron informes cruzados para todos los involucrados en la guerra. Así, en esta versión de Heribert von Feilitzsch, una sola persona fue capaz de encaminar una guerra mundial y una revolución, de modo que Madero, Villa, el ráiser alemán, los presidentes estadounidenses y una gran cantidad de empresarios y los comerciantes se convierten en los títeres de un presunto agente secreto alemán.

${ }^{1}$ Sobre la reseña de César E. Valdez al libro de Heribert von Feilitzsch, Félix A. Sommerfeld: maestro de espias en México, 1908 a 1914, publicada en LXVIII: 3 (271) (ene.-mar. 2019) de Historia Mexicana. 
Por supuesto, esto suena absurdo. El problema es que ninguno de los argumentos del crítico está en mi libro. En primer lugar, el libro no tiene nada que ver con la primera guerra mundial. Como lo sugiere el título, la historia de Sommerfeld en este libro termina en el verano de 1914. En la continuación de la biografía del agente alemán, Félix A. Sommerfeld y el Frente Mexicano en la Gran Guerra, que estará disponible en español en Penguin/ Random House el próximo año, se discutirá el desempeño de Sommerfeld durante la primera guerra mundial.

El crítico no entendió otra parte muy importante de mi libro: la tesis principal. "En la versión de Felix A. Sommerfeld: maestro de espias en México, 1908 a 1914, la ingeniería de minas, el oficio de periodista, la cercanía con Madero y el papel de traficante de armas no son más que disfraces para ocultar el auténtico objetivo: llevar a México y Estados Unidos a la guerra”. $\mathrm{El}$ argumento principal en mi libro es el contrario: antes de la primera guerra mundial, los intereses de Estados Unidos para un México estable, en el que se protegerían las comunidades e inversiones estadounidenses, coincidían con los de Alemania, que buscaba seguridad para su comunidad de inmigrantes, comercio expandido y pago de deudas. Sommerfeld utilizó esta confluencia única de intereses nacionales para promover sus objetivos, lo cual es contrario a crear una guerra entre México y Estados Unidos. Más bien, como importante asesor del presidente Francisco I. Madero y su jefe del Servicio Secreto Mexicano, Sommerfeld trabajó incansablemente para lograr el éxito del primer gobierno revolucionario. Después del asesinato de Madero, Sommerfeld trabajó nuevamente para ayudar a que la oposición a Victoriano Huerta tuviera éxito. Y de nuevo, la derrota de Huerta fue en interés tanto de Estados Unidos como del gobierno alemán.

En 1911, haciéndose pasar por un miembro de la AP News, Sommerfeld tuvo el trabajo de reducir un conflicto potencial con el ejército estadounidense en la batalla de Ciudad Juárez. También gestionó el acceso de los periodistas a Madero. Éste 
apreciaba al joven agente alemán y lo recompensó con la dirección del Servicio Secreto Mexicano. Sommerfeld trabajó bajo la supervisión de Gustavo Madero en el gobierno de Madero, el enviado alemán almirante Paul von Hintze, y Sherburne G. Hopkins, cabildero, vinculado al gobierno de los Estados Unidos y a los financieros de Nueva York. Sommerfeld no fue un hombre, como dice Valdez, "capaz de incidir directamente en las personalidades de los políticos de los países”.

Sommerfeld ayudó a derrotar a Reyes y a Orozco coordinando (a través de Hopkins y otros) el apoyo del gobierno de Estados Unidos y las finanzas para Madero. Trabajó muy de cerca con el Departamento de Justicia de los Estados Unidos y es en este contexto que su organización, el Servicio Secreto Mexicano en Estados Unidos, dirigió la mayor operación clandestina extranjera en suelo estadounidense en la historia. Valdez no entendió el contexto de este episodio. Estos no fueron "caprichos personales" sino la creación y coordinación de una cooperación intergubernamental altamente complicada.

Sommerfeld también trabajó para lograr que el gobierno alemán apoyara a Madero y lo reconociera como presidente de México. En este esfuerzo, se opuso al sentimiento del gobierno alemán y de la comunidad de inmigrantes en México. Sin embargo, convenció al embajador Von Hintze de la legitimidad y utilidad de Madero, quien a su vez convenció al gobierno alemán para que reconociera su presidencia.

Después del asesinato de Madero, en 1913, Sommerfeld se unió primero al campo de Carranza y luego al de Villa. Nuevamente ayudó a obtener apoyo político del gobierno de Estados Unidos y armas y municiones de los fabricantes estadounidenses. Esto fue posible porque los intereses de Alemania, México (constitucionalista) y Estados Unidos coincidieron en el esfuerzo de destituir al presidente usurpador Huerta. Cuando Huerta fue derrotado en 1914 y comenzó la guerra mundial, este libro termina. Valdez afirma que las actividades de Sommerfeld 
durante la guerra mundial, que no se tratan en este libro, están relacionadas con su trabajo en México en los años anteriores: "llevar a México y Estados Unidos a la guerra". Este no es el caso. La guerra mundial cambió la actitud de Sommerfeld y marcó el final de la alineación de los intereses alemanes y estadounidenses.

Valdez cuestiona mi uso de las fuentes. Lamenta la falta de más obras secundarias en el texto, especialmente las de académicos mexicanos. Aunque ciertamente habría existido la posibilidad de incorporar más fuentes secundarias en la historia, todo mi trabajo se basa únicamente en la investigación primaria para las tesis principales. Un mito común es que el gobierno alemán apoyó a Victoriano Huerta. Se inició con propaganda británica durante la primera guerra mundial, luego se transformó de propaganda en hecho histórico en el libro de Barbara Tuchman titulado El telegrama Zimmermann. Desde entonces, esto se encuentra ampliamente documentado en docenas de grandes trabajos sobre la revolución mexicana. Mi investigación independiente, basada en fuentes originales en Alemania, concluye que este mito es evidentemente falso.

Todo mi trabajo académico se basa en fuentes primarias de archivo. Valdez menciona cinco trabajos secundarios. Más de una docena de páginas de fuentes secundarias, periódicos y artículos aparecen en la bibliografía de mi libro. Cada una de estas fuentes aparece en mi libro para obtener información de antecedentes. Utilizo fuentes de archivo de México, Estados Unidos y Alemania y triangulo el contenido. Las fuentes principales son los documentos revolucionarios mexicanos, especialmente de la facción de Villa (archivos de Chihuahua antes de la Revolución, documentos de Lázaro de la Garza, de Silvestre Terrazas, de Federico Stallforth), fuentes estadounidenses (los archivos del FBI, los de los Departamentos de Justicia, Inmigración, Estado y Guerra, los documentos de Hugh Lenox Scott) y fuentes alemanas (archivos del Servicio Exterior, documentos de Emil 
Holmdahl, de Heinrich Albert, del almirante Von Hintze, de Franz von Papen, archivos de Inteligencia Naval, archivos del Departamento Imperial de Guerra). En mi libro, el interrogatorio de Sommerfeld en junio de 1918 hecho por el Departamento de Justicia de los Estados Unidos sirvió como contorno de sus actividades durante la Revolución. El uso de otras fuentes primarias apoyó sus afirmaciones, aclaró el significado de sus reclamaciones o mostró dónde mintió. Esta metodología está clara en el libro, pero tal vez no para el crítico. Al lector se le presenta evidencia de lo que sostengo en cada paso del camino y puede evaluar si es convincente o no. Las fuentes están listadas en más de 1000 notas. He puesto la colección digital de fuentes primarias utilizadas en el libro (alrededor de 98000 documentos) a disposición de varios académicos mexicanos.

Para concluir, las muchas referencias a la primera guerra mundial, el supuesto objetivo de Sommerfeld de desestabilizar las relaciones Estados Unidos-México, y otras caracterizaciones erróneas de las tesis principales en el libro suenan como si el crítico se refiriera a un libro diferente. Quizá algunas de sus preguntas serán respondidas en mi continuación, "Félix A. Sommerfeld y el Frente Mexicano en la Gran Guerra", que se publicará en México en este 2019. 
